\section{A VOICE IN THE WILDERNESS}

\section{THE "NEW ENGLAND JOURNAL OF MEDICINE" SINCE 1812}

BY

\author{
.JOSEPH GARLAND, M.D. \\ Editor, "New England Journal of Medicine"
}

An invitation from the editor of the British Medical Journal to tell, in its pages, something of the history of the New England Journal of Medicine, on the occasion of its hundred and fiftieth anniversary, was a pleasant surprise. Coming at about the time of our American Thanksgiving, it was accepted in that spirit by one who, as a confirmed amateur, has been associated in one capacity or another with the New England Journal of Medicine for many years. An amateur standing, however, has long been a sporting proposition among those of British descent, and the New England Journal may be considered as having a heritage of British standards and traditions.

John Collins Warren and James Jackson, two able and energetic young Boston physicians, were the original founders of the New England Journal of Medicine and Surgery and the Collateral Branches of Science (Conducted by a Number of Physicians), the first quarterly issue of which appeared in January, 1812. Warren, born in 1778, was the eldest son of John Warren, proposer in 1782 of a Medical Faculty at Harvard University, and its first professor, as well as a founder in the previous year of the Massachusetts Medical Society; John was a younger brother of another physician, General Joseph Warren, who lost his life at the Battle of Bunker Hill.

James Jackson, a native of Newburyport, Massachusetts, was a graduate of Harvard College a year before his friend, Warren, and was Warren's senior by a year. He studied medicine at Harvard Medical School and as an apprentice to Edward Holyoke, of Salem ; Warren pursued his medical studies less formally and at first less seriously. They both travelled to England in 1799 and served as dressers under Astley Cooper at Guy's Hospital. Jackson returned to Boston in 1800 and entered practice; Warren earned his medical degree at Edinburgh, studied for a year in Paris, and sailed for home in 1802 .

Warren and Jackson not only established the Journal. Between them they founded the Massachusetts General Hospital and obtained its charter in 1811, although its cornerstone was not laid until 1818. It was then built, according to the specifications of its trustees, "of stone and of that kind called granite," this material, through the kindness of the Massachusetts legislature, being "hammered and fitted for use" by the convicts at Charlestown.

As team mates the two friends made a going concern of the Massachusetts Medical Society, to-day the oldest of the state societies in continuous existence, and each served as its president ; they prepared for the Society the first Massachusetts Pharmacopoeia; they became, respectively, Professor of Anatomy and Surgery and Hersey Professor of the Theory and Practice of Physick at the Medical School.

As collaborators in the editing and publication of the medical journal they associated with themselves other prominent Boston physicians-Drs. John Gorhan, Jacob Bigelow, and Walter Channing, and later Drs. George Hayward, John Ware, and John W. Webster. The eight formed a club which met each month " to sup and read the papers submitted."

None of the eighty or so medical journals that had originated in the eighteenth century survived to modern times. Included in this number, and undoubtedly the first medical periodical to appear in the Western Hemisphere, was the weekly Mercurio volante, published in Mexico City, where, on October 17, 1772, it started a flight that was sustained until February of the following year.

Two early nineteenth-century journals that survived to the present day, even if with lapses, preceded the New England Journal. The Medical Museum had been founded in Philadelphia in 1804, had been discontinued in 1813 , and resumed publication in 1820. In 1827 it changed its name, becoming the still current American Journal of Medical Sciences. The Edinburgh Medical and Surgical Journal initiated its long career in January, 1805 , and, as the Edinburgh Medical Journal, continued an uninterrupted

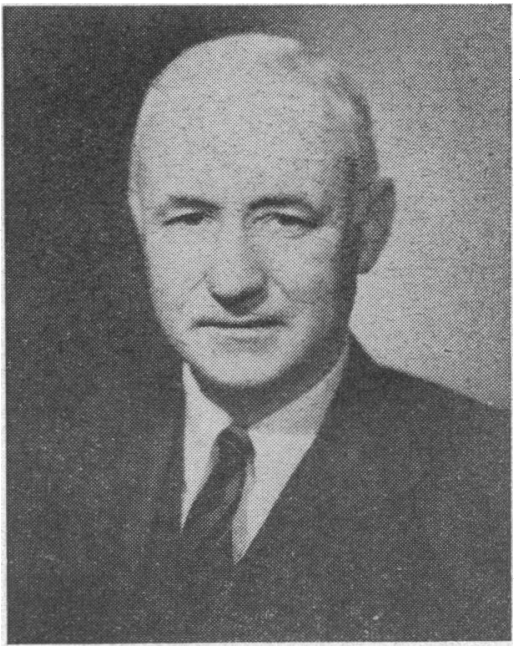

Dr. Joseph Garland. course for a hundred and fifty years, suspending operations with its December issue in 1954. A year later, as you all know, it merged with the Glasgow Medical Journal, resuming publication as the Scottish Medical Journal. Thus it becomes possible that the New England Journal of Medicine is to-day the oldest in continuous existence.

The first issue of the Journal had its remarkable features, the original articles consisting of "Remarks on Angina Pectoris," by John Warren; "Remarks on the Morbid Effects of Dentition," by James Jackson ; "Case of Apoplexy with Dissections," by John C. Warren: "Treatment of Injuries Occasioned by Fire," by Jacob Bigelow; and "Remarks on Diseases Resembling Syphilis," by Walter Channing. Nor were the collateral branches of science neglected, for in subsequent issues such titles appeared as "History of the Forest Trees of North America," translated from the French ; "Description of a Bank for Alpine Plants," "Remarks on the Importance of Inland Navigation from Boston, by the Middlesex Canal and Merrimack River," and "Description of an Elk."

The editorship of the Journal passed into the hands of Drs. Ware and Channing in 1824, and in 1827 it was continued as The New England Medical Review and Journal throughout that year.

Meanwhile, in 1823, coeval with the establishment of the Lancet by the turbulent Thomas Wakley, the weekly 
ix:

NEW ENGLAND JOURNAL.

or

WETITNK AND SUIGERY,

$x \times 10$

TII COLLATERAL DRANCUES OF SCIENCE.

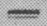

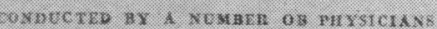

-

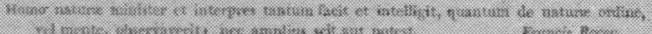

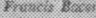

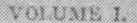

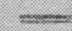

unstron

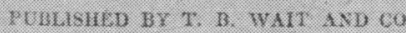

1813

Fig. 1.-1812.

Boston Medical Intelligencer made its appearance. Bravely optimistic, its introductory message ran as follows :

"In the United States, where Science is described as the palladium of national prosperity, every attempt to diffuse truth meets with a cordial reception. No study is more rapidly gaining the dignity it so obviously merits than medicine. A few years ago it was not uncommon for people to be born bone-setters, whose chirurgical celebrity was as immediate as their methods of operation were infallible. Cancer Doctors devoured the humble victims of their duplicity with a slow but certain torture ; and a seventh son, however mean, was a favourite of fortune and the peculiar gift of Providence. These scenes of ignorance are passing away. Reason, the best weapon against the absurdities that have enslaved the mind, has triumphed over bigotry and superstition."

The owners of the New England Journal met the challenge by purchasing the Intelligencer for $\$ 600$ and combining the two as the. weekly Boston Medical and Surgical Journal, the first issue of which, under the editorship of Drs. Warren, Ware, and Channing, appeared on February 19, 1828.

"As it is devoted to no party or institution [according to the original notice] the Editors offer it to the medical profession as a vehicle for such publications as they may wish to make; and they hope by it to bring out the talent of this part of the country. It is their intention to introduce the practice of the Massachusetts General Hospital, especially the surgical part, whenever anything interesting occurs in it. ... The present proprietors, having in view the utility of the work, have made it cheaper than any one of the kind containing as much matter, and as well printed."

The Journal was to continue in weekly publication under its new name for a hundred years, during which time fourscore other medical journals made their appearance in New England alone-equal to the total crop of the preceding century. Most of them disappeared after a brief surge of initial activity.

Even as the original New England Journal of Medicine had opened its pages with an astute article by his father, the Boston Medical and Surgical Journal had for its first paper "Cases of Neuralgia, or Painful Affections of Nerves," by the son. John Collins Warren was then 50 years old, and according to his biographer :

"At this period he rose in winter, and breakfasted by candle light and went directly out to visit his patients until one ; except during the lectures, when he passed usually two hours at the Medical College. From one to two he received patients at his home. He devoted about twenty minutes to his dinner; after which, he retired to his room for an hour. In the latter part of the afternoon, he visited such patients as required a second visit, and then took a cup of tea in his study at seven; after which, he wrote and worked upon the subjects before mentioned. often, if not generally, until two in the morning. The greater part of this time he devoted to the 'Medical Journal,' preparing the Hospital Records, selecting extracts from foreign journals, and writing original articles."

$130 \mathrm{ETON}$

\section{MEDICALA AND SURGICAL}

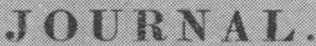

VOL. UME I.

FERTIARY, 1828-TEBRUARY, 1829

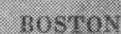

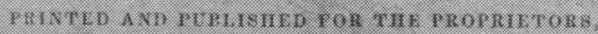

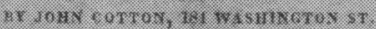

Fig. 2. -1829 . 
Dr. Warren thus guided the affairs of the Journal, well assisted, until 1835 , when he vacated the sanctum in favour of Dr. Jerome V. C. Smith, original editor of the Intelligencer. Dr. Smith carried on for twenty-two years, resigning on his election as mayor of Boston and being followed by a succession of editors. The "New Series" of the Journal, of larger size and in double column, was inaugurated in 1868 . In short, according to its own announcement, "In its present form, it will contain about one fifth more matter than before, and will conform somewhat in shape and appearance to the best modern specimens of hebdomadal literature."

True to its original commitment in regard to the collateral branches of science, it published in 1852 the account of a "Strangulated Phrenic Hernia in a Horse." Of at least equal interest, appearing in the first volume under the Boston Medical and Surgical Journal title, was an "Account of the Blowing Snake," as told in a letter from Dr. H. Conant, of Maumee, Ohio.

On the 10th of May of that year Dr. Conant had been called to visit a boy of 15 , whom he found "much swollen in his countenance, much affected with nausea and giddiness," with finally a universal prostration. An emetic-cathartic was administered, to be followed with carb. ammon. Two miles further on the doctor called on a man of 40 years of age, labouring under precisely the same symptoms. A similar prescription was given and he returned home by another road.

The next day, when going to visit these patients, he was called to a house not far from the first, where he found a girl of 14 years, similarly afflicted but more severely. Under the same treatment but with the addition of olive oil her recovery was more rapid, although not complete for several weeks.

It transpired that three days before these patients were seen " they had all been exposed to the effluvia of the

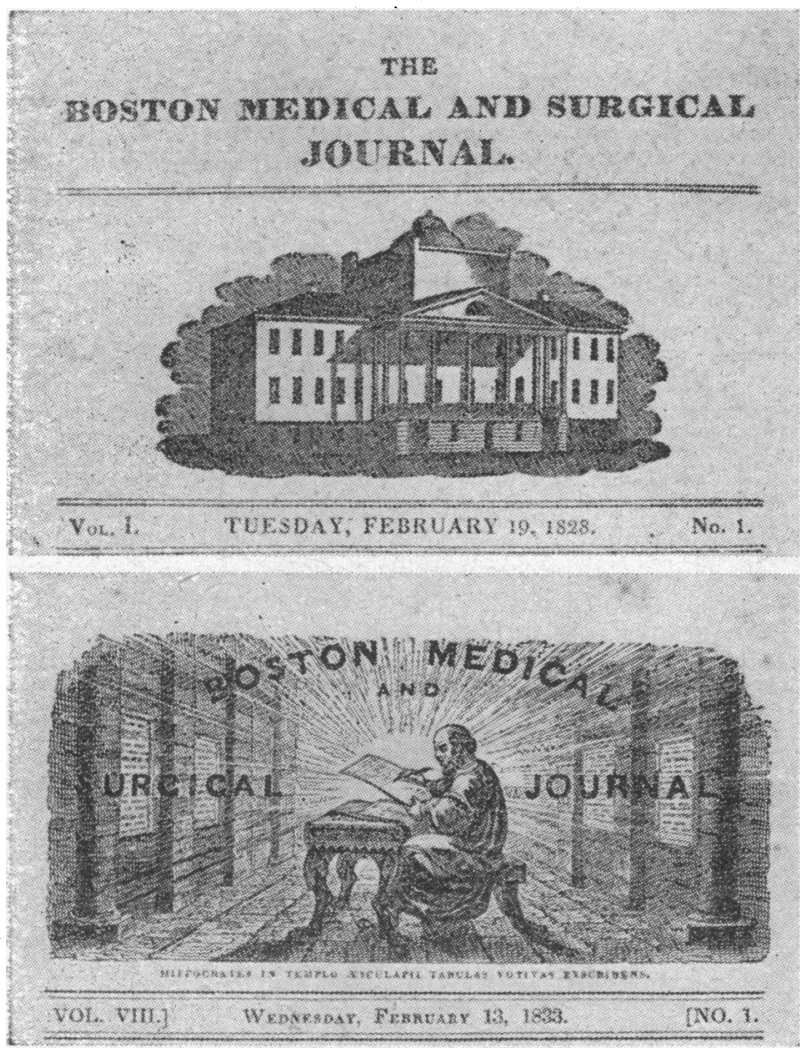

FIG. 3.-1828 (top). 1833 (bottom).

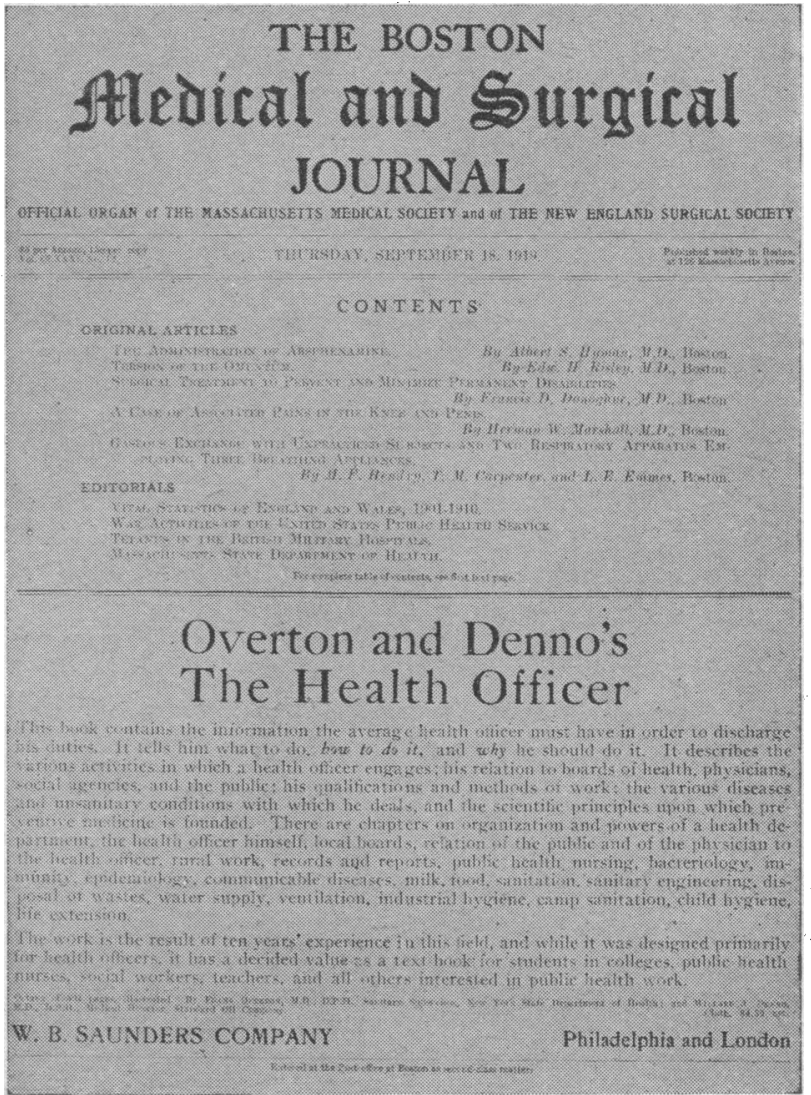

Fig. 4.-1919.

blowing snake. The man had killed two and the boy and girl had each passed one, at the distance of a yard or so to the leeward. A native Frenchman of the country, who says he has before witnessed the effects of these snakes, would not believe that these patients were affected that way. For he says, those blown upon, always swell and burst open and invariably die. ...

"The snake is about $2 \frac{1}{2} \mathrm{ft}$. long and very thick in proportion. Its color is brown, and when irritated it has yellowish cheeks. It is said, that during its expiration, a yellowish steam is visible issuing from its mouth to the distance of several inches, but I know nothing of it, having never seen a living snake of the kind."

In 1873 the Journal was purchased by " a number of public-spirited gentlemen," among them Dr. J. Collins Warren, grandson of the founder. Dr. Warren, with the assistance of Dr. Thomas Dwight, assumed the editorship, and the publication reverted for a few years to its original single-column format. During this period it campaigned successfully for the abolition of the coroner system in Massachusetts, grown corrupt, in favour of trained medical examiners. Dr. Warren retired in 1881 and was succeeded by Dr. George Brune Shattuck, who triumphed over a weekly deadline for thirty-one years, a record for endurance.

The editors entered into an agreement with the Massachusetts Medical Society in 1914 to publish its official proceedings, and in 1921 the Journal was rescued, perhaps from financial disaster, through its purchase by the Society. The change in ownership was marked by the retirement of its most brilliant editor-Dr. Robert M. Green, anatomist and surgeon, classical scholar, teacher of Greek, translator of Horace, and author of a fivevolume epic poem of the Arthurian legends. He was 
succeeded by Dr. Walter P. Bowers, a respected elder statesman, who successfully carried on his new vocation for fifteen years, until the age of $\mathbf{8 0}$.

In 1923 the Journal assumed the publication of the Case Records of the Massachusetts General Hospital, medical as well as surgical. The clinicopathological conference, as embodied in these records, was characterized by the late Dr. Alan Gregg, director of medical sciences of the Rockefeller Foundation, as "the wonder of many of our foreign visitors, who see in it a candor and fearlessness altogether to the credit of American medicine." In 1928 the centenary of the publication as the Boston Medical and Surgical Journal was observed, and it assumed its present title.

During the Journal's hundred and fifty years a few probable "firsts" have been credited to it." Mason Cogswell, of Hartford, Connecticut, reported in 1823 the first known ligation and cutting of the carotid artery -performed twenty years previously! In November and December, 1846, Henry Jacob Bigelow and John Collins Warren, respectively, reported the first demonstration before a medical group of the use of ether anaesthesia in surgery, the operation having been performed on October 16 at the Massachusetts General Hospital by the then elderly Warren. In his own cautious words he closed his paper as follows:

"Let me conclude by congratulating my professional brethren on the acquisition of a mode of mitigating human suffering, which may become a valuable agent in the hands of careful and well-instructed practitioners, even if it should not prove of such general application as the imagination of sanguine persons would lead them to anticipate."

Successful removal of the uterus through an abdominal incision was reported in 1853 by Gilman Kimball, of Lowell, Massachusetts, and in 1889 Reginald Heber Fitz published his epochal paper on "Acute Pancreatitis." James Homer Wright at the Massachusetts General Hospital described the origin of the blood platelets in 1902, and in 1936 Fuller Albright and his associates reported the new syndrome of osteitis fibrosa disseminata with areas of pigmentation and with endocrine dysfunction with precocious puberty in females.

Even a "general" or " all-purpose" medical journal has as one of its main functions to-day the publication of freshly acquired knowledge, the result of careful and accurate scientific research. It requires diversification, however, and balance in this effort, as well as having socio-economic and organizational functions to fulfil. I have often quoted from a leading article published in the British Medical Journal some years ago, and tried to establish similar standards for our own, in its more limited field.

"It is not a journal for general practitioners or consultants, or public health officers, or laboratory workers. It is a journal which aims at representing the best of British medicine in order to promote the medical and allied sciences. It tries to provide each week something for everybody, not everything for somebody."

Let us hope that neither of our journals will ever lose sight of the one objective of all medical teaching and learning and research-the prevention and treatment of disease and the personal, sympathetic care of the patient.

*Viets, H R., " A Score of Significant Papers Published in the Journal During the Last Hundred and Fifty Years," New Engl. J. Med., 1962, 266.
The following lines, found in a Boston Medical and Surgical Journal of more than a century ago, may strike a nostalgic note with some of our readers of to-day:

A Card Left on a Doctor's Door, On His Going Out to Tea

Here dwells, awaiting all the haps of life,

A doctor humble and of less conceit ;

For lofty station never was his strife,

And mammon-folly mars not his retreat.

Few are his wishes, with the world content;

His daily recompense enough, though small;

In early studies all he had he spent;

Now gains in practice oft ('twas all he hoped) a call

No farther seek him till tomorrow's dawn,

Let him, uncalled, a casual feast attend

(Where he awhile from troubling care has gone),

The supper of a neighbor and a friend.

It is certainly not my intention, even by invitation, $t=$ blow in Old England a New England horn. But perhaps I can again, as I have done before, derive some courage from Paul's First Epistle to the Corinthians: "For if the trumpet give an uncertain sound, who shall prepare himself to the battle?"

\section{To-day's Drugs}

With the help of expert contributors we publish below notes on a selection of drugs in common use.

\section{Haloperidol}

"Serenace" (G. D. Searle).

Chemistry.-The chemical name is 4'-fluoro-4-[4-hydroxy4-chlorophenyl piperidino] butyrophenone. Structural formula:

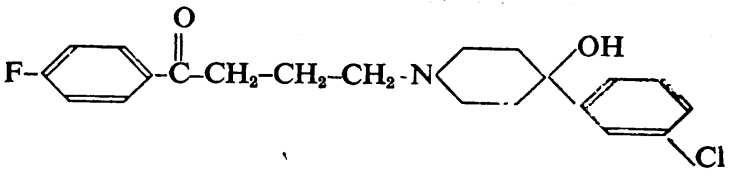

Pharmacology.-The chemical structure is closely related to gamma-amino butyric acid (G.A.B.A.), a substance found naturally in the brain. G.A.B.A. is derived from glutamic acid, a deficiency of which may result in increased motor excitability, and it has been suggested that G.A.B.A. influences functional activity in the brain through control of metabolism. Haloperidol, by competing with G.A.B.A., might thereby influence motor behaviour. But since haloperidol also influences several other amino-acids found in the brain it would be rash to speculate too much about its possible mode of action.

Therapy.-Haloperidol is a most effective drug in controlling states of agitation and excitement and is particularly valuable in the treatment of mania. Given in proper dosage it will often bring psychomotor overactivity under control within a few hours and abolish symptoms altogether after four or five days. Schizophrenic excitement may also respond well and it has been claimed that hallucinations and paranoid delusions are sometimes abolished when other treatments have failed. However, it is not a suitable drug to use alone in the treatment of acute schizophrenia. In cases of mental subnormality, both of adults and of children, restless or antisocial behaviour has been reported to respond quickly to haloperidol.

Haloperidol has little place in the treatment of agitated depression, for though agitation may be lessened the basic depressive process will be unaffected and may even be made worse. Combined with an anti-depressant drug, however, it can sometimes stabilize recurring cyclothymic illnesses which have failed to respond satisfactorily to other treatments. 